\title{
Is nitric oxide in exhaled air produced at airway or alveolar level?
}

\author{
C.A. Byrnes, S. Dinarevic, C. Busst, A. Bush, E.A. Shinebourne
}

Is nitric oxide in exhaled air produced at airway or alveolar level? C.A. Byrnes, S. Dinarevic, C. Busst, A. Bush, E.A. Shinebourne. (C)RS Journals Ltd 1997.

ABSTRACT: The aim of this study was to determine whether the nitric oxide (NO) measured in exhaled air is produced at airway or alveolar level.

Exhaled NO was measured using a chemiluminescence analyser, and carbon dioxide $\left(\mathrm{CO}_{2}\right)$ concentration using a Morgan capnograph in single exhalations in 12 healthy subjects (mean age 32 yrs; 6 males and 6 females). For each subject, five exhalations were made directly into the NO analyser and five were made through a T-piece system, which allowed measurement of expiratory flow rate.

The peak NO levels measured via the T-piece system were 41.2 (SEM 10.8) parts per billion (ppb), significantly lower than direct levels $84.8(14.0)$ ppb $(p<0.001)$. The levels of NO tended to rise to an early peak and plateau, while the $\mathrm{CO}_{2}$ levels continued to rise to peak late in the exhalation. The mean times to reach peak NO levels were $32.2 \mathrm{~s}$ (direct) and $23.1 \mathrm{~s}$ (T-piece), which were significantly different from that of peak $\mathrm{CO}_{2}$ levels $50.5 \mathrm{~s}$ (direct) and $51.4 \mathrm{~s}(\mathrm{~T}$-piece) $(\mathrm{p}<0.001)$. At peak NO level, the simultaneous $\mathrm{CO}_{2}$ level, mean $4.9 \%$ (SEM 0.14 )\%, was significantly lower than the peak $\mathrm{CO}_{2}$ reached, $5.8(0.21) \%(\mathrm{p}<0.001)$.

We conclude that peak nitric oxide levels are dependent on measurement conditions. There are significant differences between the time to peak of carbon dioxide and nitric oxide. Therefore, most nitric oxide, unlike carbon dioxide, is produced in airways and not at alveolar level.

Eur Respir J 1997; 10: 1021-1025.
Paediatric Dept, Royal Brompton Hospital, London, UK.

Correspondence: C.A. Byrnes

Paediatric Respiratory Dept

Royal Brompton Hospital

Sydney St

London W11 2AH

UK

Keywords: Airway inflammation chemiluminescence

exhalation

nitric oxide

Received: April 251996

Accepted after revision January 231997
Nitric oxide can be measured in exhaled air [1, 2], and has been shown to be produced by airway epithelial cells, vascular endothelial cells, macrophages, neutrophils and fibroblasts $[3,4]$. The source of nitric oxide (NO) within the respiratory tract continues to be debated. Initially, BORLAND et al. [5] suggested that the NO measured in exhaled air from a single full exhalation and during tidal breathing was of alveolar origin, like carbon dioxide $\left(\mathrm{CO}_{2}\right)$. PERSSON et al. [6] suggested that $\mathrm{NO}$ was formed preferentially in the small airways, such as the terminal and respiratory bronchioles. By comparing the levels of NO exhaled during tidal breathing either through the nose or the mouth, Alving et al. [7] suggested that the major contribution came from the nasal space, with a minor addition from the lower airways. LunDBERG et al. [8] demonstrated a decreasing concentration of exhaled NO when sampling progressively down the respiratory tract at the nose, mouth and, in four tracheostomized patients, below the vocal cords. By isolating the nasal passages from the rest of the respiratory tract with the use of voluntary closure of the soft palate, KIMBERLy et al. [9] showed that the release of NO in the nasal passages was approximately seven times that of the rest of the respiratory tract. Extremely high levels of NO have now been demonstrated in the paranasal sinuses, with an age-dependent increase in keeping with sinus pneumatization [10]. It may be the sinus production of NO which communicates with the nasal spaces, that gives rise to the high levels of NO measured in the nasal cavity.

The aim of this study was to ascertain the level of the source of NO in exhaled air within the respiratory tract.

\section{Methods}

\section{Subjects}

Twelve healthy volunteers aged $17-42$ years (mean 32 yrs; 6 males and 6 females) were recruited. They were nonsmokers, nonatopic, with no history of respiratory or cardiac disease and receiving no medication. They had normal spirometry (Compact Vitalograph; Vitalograph Ltd, Buckingham, UK).

\section{Equipment}

Exhaled NO was measured using a chemiluminescence analyser (Model 2107; Dasibi Environmental Corporation, Glendale, CA, USA), sensitive to NO from 2-4,000 parts per billion ( $\mathrm{ppb}$ ), and adapted for on-line recording of NO concentration. The NO analyser sampled at $240 \mathrm{~mL} \cdot \mathrm{min}^{-1}$. The $\mathrm{CO}_{2}$ levels were measured with a Morgan capnograph PK Morgan, Kent, UK. The $\mathrm{CO}_{2}$ analyser sampled at $200 \mathrm{~mL} \cdot \mathrm{min}^{-1}$. Both the $\mathrm{NO}$ and $\mathrm{CO}_{2}$ analysers were calibrated before and after each 
subject, with known amounts of the appropriate gases. Mouth pressure was measured using a Medex Straingauge pressure transducer (Medex Medical Inc., Rossendale, UK) through a Galtec pressure amplifier (Galtec Ltd, Isle of Skye, UK) in $\mathrm{mmHg}$. Flow was measured via a Platon Flow Meter to a low flow pneumotachograph (CT Platon Ltd, Basingstoke, UK) and a GM Electrospirometer (GM Instruments Ltd, Kilwinning, UK). The signal for each of these four separate measurements was then displayed on a Linseis chart recorder (Linseis Ltd, Cambridge, UK).

Preliminary experiments were conducted to determine the delay time (time for the sample to get down the tube to the analyser) and response time (in this case $0-95 \%$ rise time) of a square wave for both analysers. Briefly, a three-way tap connected to an oscilloscope was turned, allowing test gas to flow down the apparatus at a rate comparable to the subjects expiratory flow rate $(500$ $\left.\mathrm{mL} \cdot \mathrm{min}^{-1}\right)$, starting at the subject's mouthpiece. The output of the analysers was displayed on the same oscilloscope. The delay time was the time between throwing the switch and the onset of the analyser signal, and the rise time was the time from onset of the signal to $95 \%$ of the plateau value. The experiment was repeated 10 times in all. In our preliminary experiment [11], we demonstrated a good correlation, similar to that of other groups [12], between the peak NO and area under the curve (AUC). The peak NO was taken for these experiments. To see if different rates of flow actually generated different pressures, the calibration NO gas was applied to the analysers at a range of pressures from 4 to $40 \mathrm{mmHg}$. This resulted in an elevation of only 5.6 ppb with a 10 fold elevation in pressure.

\section{Procedure}

Each subject, wearing a noseclip, made 10 single consecutive exhalations from total lung capacity (TLC), each recording separated by $3 \mathrm{~min}$. Five of the recordings, when the subject exhaled directly into the NO analyser, were made with measurements of $\mathrm{NO}, \mathrm{CO}_{2}$ and mouth pressure. Five recordings were made using a T-piece, to allow the additional measurement of flow. The subjects controlled their expiratory flow rates voluntarily using as feedback the signal observed from the pneumotachograph. The mouth pressure was standardized to $4 \mathrm{mmHg}$. In the direct method, the combined analysers sampled at $440 \mathrm{~mL} \cdot \mathrm{min}^{-1}$ and, with the T-piece method, flow was standardized at an additional $225 \mathrm{~mL} \cdot \mathrm{min}^{-1}$ (total $665 \mathrm{~mL} \cdot \mathrm{min}^{-1}$ ). Subjects were randomized to carry out either direct or T-piece measurements first. The background level of NO was noted on each occasion, and studies were postponed if the background NO level was greater than $15 \mathrm{ppb}$.

The study was approved by the Brompton Hospital Ethics Committee and informed consent was obtained from each of the subjects.

\section{Statistical analysis}

Results were analysed using the Statistical Products and Service Solutions (SPSS) package, and employing Students t-test for matched pairs. A p-value of less than 0.05 was considered significant.

\section{Results}

Delay time for the NO analyser was 5.9 (SEM 0.8) s, and $95 \%$ response time was $1.1(0.1) \mathrm{s}$. For the $\mathrm{CO}_{2}$ analyser the delay time was $0.11(0.003) \mathrm{s}$ and the $95 \%$ response time was 41.5 (2.9) $\mathrm{ms}$. Thus, the NO analyser responded much more slowly than the $\mathrm{CO}_{2}$ analyser. Response time for the pressure transducer was $7.3(0.2)$ $\mathrm{ms}$ and for the flow meter was 40.2 (0.8) $\mathrm{ms}$, with no significant time delay. When comparing the NO and $\mathrm{CO}_{2}$ recordings, allowance was made for the difference in time delay of the measurements from each machine and for the $2 \mathrm{~mm}$ offset of the pens on the recorder.

Ten measurements were performed successfully on each of the subjects. The coefficient of variation $(\mathrm{CV})$ for individuals was $17 \%$ for the direct method and $11 \%$ for the T-piece method. The direct mean peak concentration of NO was 84.8 (SEM 14.0) ppb (range 25.1-189.0 $\mathrm{ppb})$. There was greater variation in the female subjects, mean 92.4 (36.9) ppb (range 26.2-189.0 ppb), than male subjects, mean 71.7 (28.7) ppb (range 25.1-141.0 ppb). The peak NO levels measured through the T-piece system

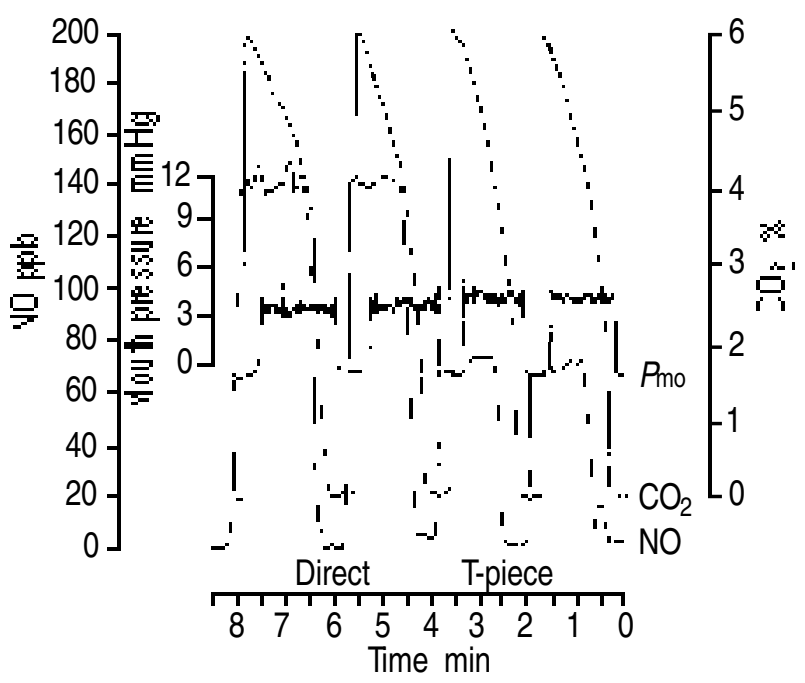

Fig. 1. - An example of raw data from one subject showing nitric oxide $(\mathrm{NO})$, carbon dioxide $\left(\mathrm{CO}_{2}\right)$ and mouth pressure $(P$ mo $)$. Note the difference in the exhaled NO concentration between the two methods of measurement.

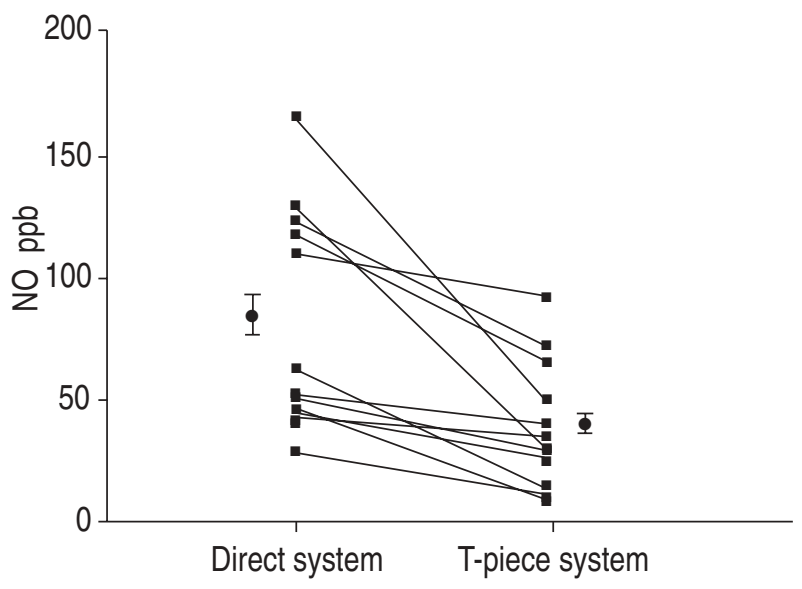

Fig. 2. - Comparison of mean peak exhaled nitric oxide (NO) levels measured through the direct and T-piece systems $(n=12)$. Each point is the mean of five exhalations. Solid circles and vertical lines show mean and SEM, respectively. 
were lower (figs. 1 and 2), with: total subject mean 41.2 (10.8) ppb (range 10.00-101.6 ppb); mean in males 33.2 (8.4) ppb; and mean in females 50.7 (12.3) ppb. There was no significant difference between peak $\mathrm{CO}_{2}$ level with direct or T-piece measurements (mean $5.81 \mathrm{vs}$ $6.19 \% ; \mathrm{p}=0.66$ ), or between male and female subjects (5.84 vs $5.75 \%$ direct $(\mathrm{p}=0.64)$; and 6.41 vs $6.03 \% \mathrm{~T}$ piece $(\mathrm{p}=0.44))$.

In the direct measurements, the mean time to reach peak NO was 32.2 (SEM 4.3) s. This was significantly less $(\mathrm{p}<0.001)$ than the mean time to reach peak $\mathrm{CO}_{2}$ levels at $50.5(5.3) \mathrm{s}$, which was also less than the time to total exhalation of $56.2(5.4) \mathrm{s}(\mathrm{p}<0.001)$ (fig. 3a). In the T-piece measurements, the mean time to reach peak NO was 23.1 (SEM 4.4) s. This was significantly less $(\mathrm{p}<0.001)$ than the mean time to reach peak $\mathrm{CO}_{2}$ levels at 51.4 (4.6) s, which was again less than the total duration of exhalation 53.5 (4.7) $\mathrm{s}$ ( $\mathrm{p}=0.14$ ) (fig. 3b). There was a significant difference in the mean time to reach peak NO levels between the direct and T-piece method $(\mathrm{p}<0.001)$, whilst there was no difference between the time to reach $\mathrm{CO}_{2}$ peaks between the direct and T-piece methods $(\mathrm{p}=0.5)$. The $\mathrm{CO}_{2}$ level measured

a)

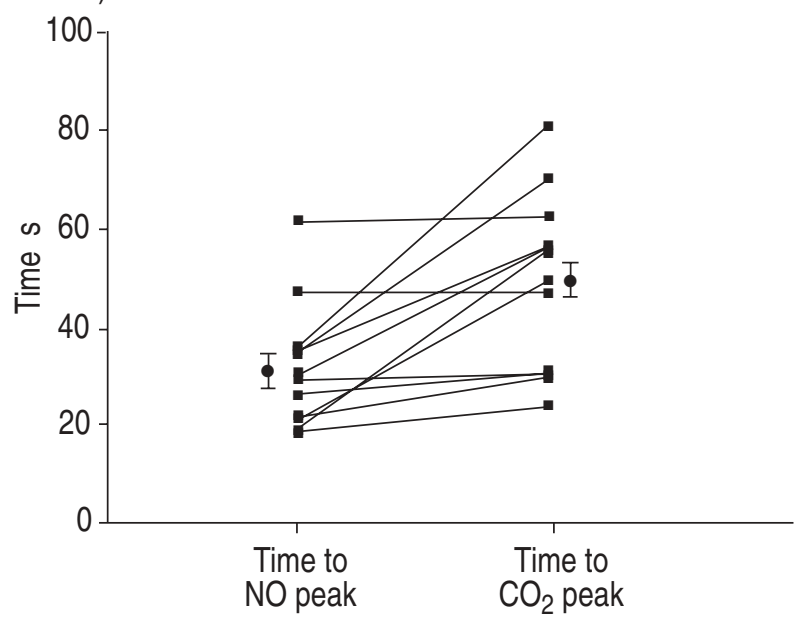

b)

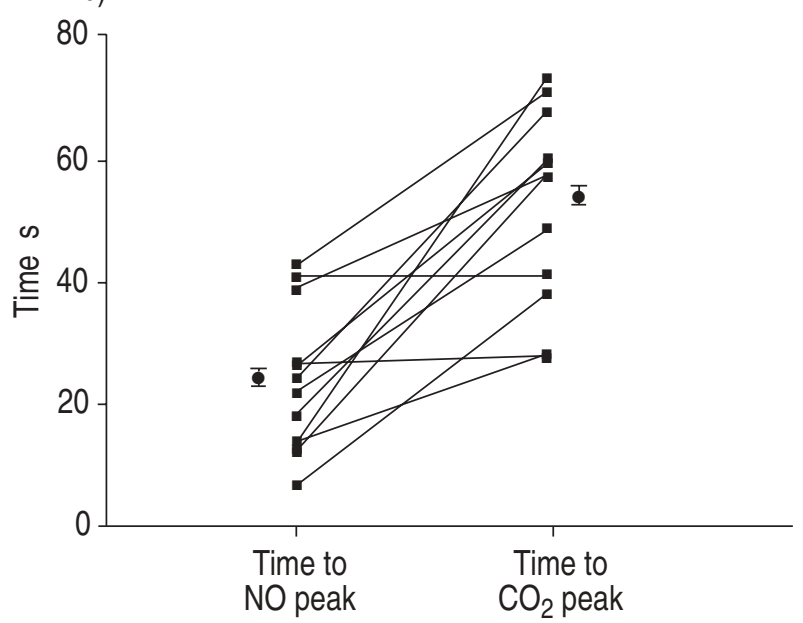

Fig. 3. - Mean time taken to reach peak nitric oxide (NO) and peak carbon dioxide $\left(\mathrm{CO}_{2}\right)$ concentrations: a) in the direct system $(\mathrm{n}=12)$; and $b)$ in the T-piece system $(n=12)$. Each point is the mean of five exhalations. Solid circles and vertical lines show mean and SEM, respectively. at peak NO was 4.88 (SEM 0.14 )\%, which was significantly lower $(\mathrm{p}<0.001)$ when compared with peak $\mathrm{CO}_{2}$ at $5.84(0.21) \%$.

The background level of NO ranged 1-11 ppb, which did not alter the conclusions and so was not taken into account in the calculations.

\section{Discussion}

Previous studies have been unable to agree whether $\mathrm{NO}$ is of alveolar or airway origin [5-7]. If $\mathrm{CO}_{2}$ and NO were both of alveolar origin, the time to peaks and the ratio of peak $\mathrm{NO}$ to $\mathrm{CO}_{2}$ would remain the same even if measurement conditions were varied. We thus measured exhaled $\mathrm{CO}_{2}$ and $\mathrm{NO}$ using two different conditions. In the direct experiments, the subjects exhaled directly into the $\mathrm{NO}$ analyser at $440 \mathrm{~mL} \cdot \mathrm{min}^{-1}$, whilst in the indirect studies, exhalation was into a T-piece system at a faster rate of $665 \mathrm{~mL} \cdot \mathrm{min}^{-1}$. The time to reach peak $\mathrm{CO}_{2}$ level, and the level of the peak $\mathrm{CO}_{2}$ were the same in both manoeuvres. However, the NO traces were very different. Firstly, the time to reach peak $\mathrm{NO}$ was shorter than the time to peak $\mathrm{CO}_{2}$ in both manoeuvres (32.2 versus $50.5 \mathrm{~s}$ in direct measurements, and 23.1 versus $51.4 \mathrm{~s}$ in T-piece measurements). Secondly, altering the rate of exhalation alters the time to peak NO independent of the time to peak $\mathrm{CO}_{2}$. Thirdly, at peak $\mathrm{NO}$ levels, the $\mathrm{CO}_{2}$ levels were below their maximal peak. Fourthly, the ratio of peak NO to peak $\mathrm{CO}_{2}$ differed between the two methods of measurement. Thus, although it is possible that a small amount of NO is of alveolar origin, the bulk of NO must be produced proximal to the alveolar membrane.

In any physiological study, it is important to consider whether the choice of apparatus or the manoeuvre selected could have significantly affected the conclusions. Ideally, we would have used fast-response time analysers, with identical delay times. Fast-response time analysers for NO have been used by others. PERSSON et al. [6] used a NO analyser with an integration time of $0.01 \mathrm{~s}$ for a study of changes in NO at rest and on exercise, and came to similar conclusions to ourselves despite using a very different analyser and manoeuvre. Our analyser would have been unable to detect rapid transient changes in NO. However, had these occurred, and they have not been described by other workers, they would have strengthened rather than detracted from our conclusions. Rapid transients have not been described for $\mathrm{CO}_{2}$, and their presence in the NO signal would have implied a different source, which is the main conclusion of the present paper. Our method gives individual CVs similar to those of other groups [12].

We considered the possibility that differing pressures exerted on the NO analyser may have accounted for the difference in readings. In a series of experiments [13], we have shown that changes in pressure between 4 and $16 \mathrm{mmHg}$ did not affect the analyser reading. Furthermore, we were careful to standardize to a mouth pressure of $4 \mathrm{mmHg}$ during the expiratory manoeuvre, to eliminate the possibility of this artefact. The pressure drop from mouth to analyser was measured both for direct and T-piece apparatus, and found to be essentially the same. The expiratory flow rates between the two manoeuvres were deliberately different, to try to 
separate the $\mathrm{CO}_{2}$ and $\mathrm{NO}$ signals. However, the flow to the analyser remained constant throughout the study.

We also considered how the different response times of the analysers could have affected our conclusions. Ideally we would have used a mass spectrophotometer and equal analyser response times. The NO response was slower, but the NO peaked first. Had the NO response time been the same as that of the $\mathrm{CO}_{2}$ analyser, the NO peak would have been even earlier. Thus, the analyser differences would serve to obscure, not enhance our conclusions.

We elected to study a single slow exhalation for the purposes of these studies, accepting that it may not be physiological or necessarily the best method for clinical practice. However, it was designed to supply an answer to the question posed. The possibility exists that the results were affected by back-diffusion of alveolar NO into the alveolar capillary blood, and by nasal contamination of the exhalate. During a prolonged expiration, if alveolar epithelium were the source of $\mathrm{NO}$, then back-diffusion would allow some to be carried away combined with haemoglobin. However, although this could affect the height of the NO peak, it is inconceivable that it could affect the time to reach peak, and thus our conclusions are unaffected. Furthermore, the total time of expiration was very similar in the two different manoeuvres, suggesting that, were this mechanism to be operative, it would apply equally between the two tests.

Higher levels of NO are produced by the paranasal $[10,14]$ and nasal spaces, when compared to oral [7-9], sites, and these contribute a major proportion of the NO concentration measured by oral exhalation. Indeed, the paranasal sinuses also contribute a major proportion of the NO concentration measured by nasal exhalation [10, 14]. However, if all of the NO came from the nasopharyngeal region then the pattern of the exhaled NO trace would be expected both to peak and fall off early, rather than the continued plateau seen in our experiments. NO can be measured in exhaled air of tracheostomized rabbits (measured by chemiluminescence), guinea-pigs (measured by Quattro mass spectrometry) [15], and in humans (measured by chemiluminescence) [8]. We attempted to exclude nasal contamination by asking the subject to wear a noseclip, and to exhale against a moderate resistance ( $4 \mathrm{mmHg}$ ). One group has used nasal suction combined with an (amplitude unstated) expiratory resistance [16], and another has excluded nasal NO contamination by voluntary closure of the soft palate [9], but these techniques are by no means universally used. Whereas we cannot exclude a degree of nasal contamination, we believe that our technique will have excluded most contamination, and that, in any case, the degree of contamination will have been identical because of the very careful standardization of experimental conditions, including expiratory mouth pressure. This study was not designed to differentiate nasal and bronchial sources of NO. We elected to analyse the peak NO rather than AUC. The two are, in any case, closely correlated [11, $12]$, We aimed to determine the sources of the two gases, not the total amounts produced, which we would expect to be independent of the experimental conditions. Thus, the difference in behaviour of the peak signals as the experimental conditions change gives more useful information than the AUC.
It might be argued that if airways (of volume $200 \mathrm{~mL}$ ) contribute a peak $\mathrm{NO}$ at $85 \mathrm{ppb}$, a total of $10^{-10} \mathrm{~mol}$, and the alveolar expirate (4 L) a plateau of $60 \mathrm{ppb}$, a total of $10^{-8} \mathrm{~mol}$, then most NO comes from the alveoli. This assumes that subjects exhaled to residual volume, which is not the case. Furthermore, if this model was correct, peak $\mathrm{CO}_{2}$ (definitely alveolar) and peak NO should move in the same direction as experimental conditions vary; in fact, the reverse was seen (fig. 2). In eight subjects, peak NO fell using the T-piece whilst $\mathrm{CO}_{2}$ rose; in the other four subjects, peak NO fell and peak $\mathrm{CO}_{2}$ remained the same. It is impossible to account for this on a model of major alveolar production of NO. The model that best accounts for the present data is continuous airway production of NO, diluted variably in a flow-dependent manner by NO-free (or low concentration NO) alveolar gas, analogous with a gaseous phase dye dilution method. The present data cannot exclude that alveolar gas contains a small amount of NO.

We have also demonstrated that the conditions of measurement critically affect the NO levels obtained. Thus, both the time to reach the NO peak and the peak level of NO reached were quite different in the two methods used in this study, although the patterns of the traces were similar. We considered whether the difference in results could have been artefactual, due to minor differences in the apparatus used in the two techniques. Teflon tubing, which does not absorb NO, connected the mouthpiece to the NO analyser. In the T-piece system, there was a $2.5 \mathrm{~cm}$ extension of plastic tubing leading from the mouthpiece to the actual T-piece, with the Teflon tubing then leading to the NO analyser off one arm, and further tubing off the second arm passing directly to the pneumotachograph for flow analysis. This would seem unlikely to account for the magnitude of differences obtained. The other alteration was that in the indirect method the flow rate was increased from 440 to $665 \mathrm{~mL} \cdot \mathrm{min}^{-1}$. This may have been enough to account for the different results.

Clearly, there are major and unexplained differences between different studies. Our results show that the levels of NO measured in exhalate are critically dependent on measurement conditions. This could be related to expired flow rates but other factors may be important. It has been suggested that orally exhaled NO concentrations correlate with the inhaled ambient concentrations of NO [17], although we found, in a subsequent experiment, that a high ambient NO level rendered NO levels difficult to interpret [18]. The present study was only undertaken if the ambient NO levels were low. Furthermore, the greater NO levels and wider variations seen in females in the present study may be due to the reported effect of the menstrual cycle [19] on exhaled peak NO concentrations. This was not controlled for in the present study. However, as the measurements were performed sequentially on each subject on the same day, the conclusions concerning the origin of NO are not affected by phases of the menstrual cycle.

Much research is being carried out on levels of nitric oxide in exhaled air in health and in different respiratory and pulmonary vascular diseases. It is important to understand where and at what level nitric oxide is being generated so that abnormal results can be interpreted correctly. 


\section{References}

1. Archer S. Measurement of nitric oxide in biological models. FASEB J 1993; 7: 349-361.

2. Leone AM, Gustafsson LE, Francis PL, Persson MG, Wikland NP, Moncada S. Nitric oxide is present in exhaled breath in humans: direct GC-MS confirmation. Biochem Biophys Res Commun 1994; 201: 883-887.

3. Barnes PJ. Nitric oxide and airways. Eur Respir J 1993; 6: $163-165$

4. Nathan C. Nitric oxide as a secretory product of mammalian cells. FASEB J 1992; 6: 3051-3064.

5. Borland C, Cox Y, Higenbottam T. Measurement of exhaled nitric oxide in man. Thorax 1993; 48: 1160-1162.

6. Persson MG, Wicklund NP, Gustafsson LA. Endogenous nitric oxide in single exhalation and the change during exercise. Am Rev Respir Dis 1993; 148: 1210-1214.

7. Alving K, Weitzberg E, Lundberg JM. Increased amount of nitric oxide in air of asthmatics. Eur Respir J 1993; 6: $1368-1370$.

8. Lundberg JON, Weitzberg E, Nordvall SL, Kuylenstierna R, Lundberg JM, Alving K. Primarily nasal origin of exhaled nitric oxide and absence in Kartagener's Syndrome. Eur Respir J 1994; 7: 1501-1504.

9. Kirnberly B, Nejadnik B, Giraud G, Holden WE. Nasal contribution to exhaled nitric oxide at rest and during breathholding in humans. Am J Respir Crit Care Med 1996; 153: 829-836.

10. Lundberg JON, Farkas-Szallasi T, Weitzberg E, et al. High nitric oxide production in human paranasal sinuses. Nat Med 1995; 1 (4): 370-373.

11. Byrnes CA, Bush A, Shinebourne EA. Measuring expi- ratory nitric oxide in humans. Methods Enzymol 1996; 269(Part b): 459-473.

12. Kharitonov SA, Yates D, Robbins RA, Logan-Sinclair R, Shinebourne EA, Barnes PJ. Increased nitric oxide in exhaled air of asthmatic patients. Lancet 1994; 343: 133-135.

13. Dinarevic S, Byrnes CA, Bush A, Shinebourne EA. Measurement of expired nitric oxide levels in children. Pediatr Pulmonol 1996; 22: 396-401.

14. Lundberg JON, Rinder J, Weitzberg E, Lundberg JM, Alving K. Nasally-exhaled nitric oxide in humans originates mainly in the paranasal sinuses. Acta Physiol Scand 1994; 152: 431-432.

15. Gustafsson LA, Leon LM, Persson MG. Endogenous nitric oxide is present in exhaled air of rabbits, guineapigs and humans. Biochem Biophys Res Commun 1991; 181: 852-857.

16. Silkoff P, Maurer J, Kesten S, et al. A technique to minimise the contribution of nasal nitric oxide to exhaled nitric oxide measured at the mouth in humans. Am J Respir Crit Care Med 1995; 151 (4, part 2): A329.

17. Dotsch J, Demirakca S, Terbak HG, Huls G, Rascher W, Kuhl PG. Airway nitric oxide in asthmatic children and patients with cystic fibrosis. Eur Respir J 1996; 9: 2537-2540.

18. Byrnes CA, Dinarevic S, Busst CA, Shinebourne EA, Bush A. Measurement conditions critically affect measured peak exhaled nitric oxide levels. Thorax 1997; (in press).

19. Kharitonov SA, Longan-Sinclair RB, Busst CM, Shinebourne EA. Peak expiratory nitric oxide differences in men and women: relation to the menstrual cycle. Br Heart J 1994; 72: 243-245. 